\title{
Motor Deficit in a Tauopathy Model Is Induced by Disturbances of Axonal Transport Leading to Dying-Back Degeneration and Denervation of Neuromuscular Junctions
}

\author{
Emilie Audouard, ${ }^{*}$ Laura Van Hees, ${ }^{*}$ Valérie Suain, ${ }^{*}$ Zehra Yilmaz, ${ }^{*}$ Luc Poncelet, ${ }^{\dagger}$ Karelle Leroy, ${ }^{*}$ and Jean-Pierre Brion ${ }^{*}$
}

From the Laboratory of Histology, Neuroanatomy, and Neuropathology, ${ }^{*}$ Neuroscience Institute, and the Laboratory of Anatomy, Biomechanics and Organogenesis, ${ }^{\dagger}$ Faculty of Medicine, Université Libre de Bruxelles, Brussels, Belgium

\author{
Accepted for publication \\ June 29, 2015. \\ Address correspondence to \\ Jean-Pierre Brion, M.D., \\ Ph.D., Laboratory of Histol- \\ ogy, Neuroanatomy and \\ Neuropathology, ULB Neuro- \\ science Institute, Université \\ Libre de Bruxelles, 808 route \\ de Lennik, 1070 Brussels, \\ Belgium. E-mail: jpbrion@ \\ ulb.ac.be.
}

\begin{abstract}
Several neurodegenerative diseases are characterized by both cognitive and motor deficits associated with accumulation of tau aggregates in brain, brainstem, and spinal cord. The Tg30 murine tauopathy model expresses a human tau protein bearing two frontotemporal dementia with Parkinsonism linked to chromosome 17 pathogenic mutations and develops a severe motor deficit and tau aggregates in brain and spinal cord. To investigate the origin of this motor deficit, we analyzed the age-dependent innervation status of the neuromuscular junctions and mutant tau expression in Tg30 mice. The human transgenic tau was detected from postnatal day 7 onward in motoneurons, axons in the sciatic nerve, and axon terminals of the neuromuscular junctions. The development and maturation of neuromuscular junctions were not disrupted in $\operatorname{Tg} 30$ mice, but their maintenance was disturbed in adult $\operatorname{Tg} 30$ mice, resulting in a progressive and severe muscle denervation. This muscle denervation was associated with early electrophysiological signs of muscle spontaneous activities and histological signs of muscle degeneration. Early loss of synaptic vesicles in axon terminals preceding motor deficits, accumulation of Gallyas-positive aggregates, and cathepsin-positive vesicular clusters in axons in the sciatic nerve suggest that this denervation results from disturbances of axonal transport. This physiopathological mechanism might be responsible for motor signs observed in some human tauopathies, and for synaptic dysfunction resulting from alterations at the presynaptic level in these diseases. (Am J Pathol 2015, 185: 2685-2697; http://dx.doi.org/10.1016/j.ajpath.2015.06.011)
\end{abstract}

Tauopathies are a class of neurodegenerative diseases characterized by the presence of aggregates of abnormally hyperphosphorylated forms of the microtubule-associated protein tau (MAPT) in nerve cells and/or glial cells. ${ }^{1}$ Tauopathies include Alzheimer disease, some forms of frontotemporal lobar degeneration, Pick's disease, progressive supranuclear palsy, and corticobasal degeneration, among others. Several of these tauopathies are characterized by both cognitive and motor deficits and tau pathology in brain, brainstem, and spinal cord. Frontotemporal lobar degeneration patients can develop both dementia and a motoneuron disease with loss of motoneurons in spinal cord. ${ }^{2}$ The Guam amyotrophic lateral sclerosis/Parkinsonism-dementia complex is characterized by a motor neuron disease with widespread neurofibrillary tangles (including some in the spinal cord), Parkinsonism, and

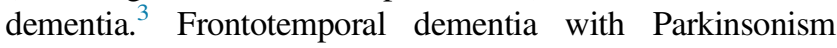
linked to chromosome 17 (FTDP-17) is caused by mutations in the MAPT gene ${ }^{4}$ and presents with behavioral, language, and motor abnormalities.

Tau is mainly expressed in neuron, and its primary function, by binding to microtubules, is to regulate or

\footnotetext{
Supported by the Diane program (Walloon region) (816856) and by grants from the Belgian Fonds de la Recherche Scientifique Médicale (T.0023.15), the Fund Aline (King Baudoin Foundation), the Foundation for Alzheimer Research (FRA/SAO; 14001) and performed in the frame of the IAP program (P7/16) of the Belgian Federal Science Policy Office.

Disclosures: None declared.
} 
modulate the stability of axonal microtubules. Other functions of tau include a role in signal transduction, the regulation of axoplasmic transport, and interaction with actin cytoskeleton. ${ }^{6,7}$ FTDP-17 tau mutations reduce the ability of tau to interact with microtubules, promote the assembly of tau into filaments, or perturb the normal ratio of tau isoforms, leading to abnormal aggregation of tau. ${ }^{4}$

Expression of FTDP-17-associated mutant tau proteins in transgenic mice induces development of tau pathology and neurofibrillary tangles, and several of these models develop motor deficits. ${ }^{8-10}$ To better understand the development of motor impairment in tauopathies, we have analyzed the age-dependent expression of mutant tau and the age-dependent innervation status of the neuromuscular junction in the Tg30tau transgenic model. Tg30tau transgenic mice express a human tau protein bearing two FTDP17 pathogenic mutations (P301S and $\mathrm{G} 272 \mathrm{~V})^{11}$ in the forebrain and in the spinal cord and develop tau pathology and neurofibrillary tangles. ${ }^{10} \mathrm{Tg} 30$ tau mice develop a severe motor deficit beginning at 8 months, an axonopathy and severe muscle atrophy. We observed that the expression of human transgenic tau impaired the maintenance of neuromuscular junctions (NMJ), leading to muscle denervation in $\mathrm{Tg} 30$ mice. Loss of synaptic vesicles at the NMJ and accumulation of tau inclusions and cathepsin-positive vesicles suggest the existence of disturbance of axonal transport in the sciatic nerve of $\mathrm{Tg} 30$ mice. Similar alterations might explain the development of a motoneuron phenotype in some human tauopathies.

\section{Materials and Methods}

\section{Animals}

Tg30tau transgenic mice were generated and characterized as described. ${ }^{10,11}$ Briefly, these mice express a 1N4R human tau isoform mutated at positions G272V and P301S, under the control of a Thyl promoter. Only heterozygous animals were used here, and nontransgenic littermates were used as wild-type (WT) controls. Mice were genotyped by PCR as reported. ${ }^{12}$ All mice were maintained on a 12-hour lightdark cycle, with food and water ad libitum. All studies on animals were performed in compliance and following approval of the ethical committee for the care and use of laboratory animals of the medical School of the Free University of Brussels.

\section{Tissue Preparation}

Newborn and adult mice were sacrificed by decapitation or cervical dislocation, respectively. The brain, the lumbar portion of the spinal cord, sciatic nerve, and left hindlimb muscles were dissected and then formalin-fixed overnight at room temperature. Samples were embedded in paraffin and cut at $7 \mu \mathrm{m}$ thickness using a microtome (Leica Leitz 1400; Leica Microsystems, Diegem, Belgium). Right hindlimb muscles were fixed in $4 \%$ paraformaldehyde in phosphate-

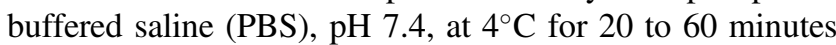
according to their developmental stage. After fixation, the tissues were rinsed three times in PBS and then cryoprotected in 20\% sucrose/PBS for 48 hours. Tissues were embedded in Tissue Tek (Prolabo; VWR International, Leuven, Belgium) and cut at $20 \mu \mathrm{m}$ thickness using a cryostat (Leica CM3050 S). Cryosections were dried at room temperature and stored at $-20^{\circ} \mathrm{C}$.

\section{Immunofluorescence Labeling of Neuromuscular Junctions}

Muscle cryosections (tibialis anterior, gastrocnemius, and quadriceps) were treated with $0.1 \mathrm{~mol} / \mathrm{L}$ glycine in PBS for 30 minutes before processing. After washes with PBS, sections were permeabilized with PBS/0.3\% TritonX-100 for 10 minutes and treated with $\mathrm{PBS} / 10 \%$ horse serum/ $/ .1 \%$ Triton (buffer A) for 1 hour at room temperature. The primary antibodies were diluted in the buffer $\mathrm{A}$ and incubated overnight at $4^{\circ} \mathrm{C}$ on tissue sections. After washes in PBS/Triton $0.1 \%$, the secondary antibodies and $\alpha$-bungarotoxin (BTX) were diluted in buffer A and incubated on tissue sections for 1 hour at room temperature. After washes in PBS/Triton $0.1 \%$, the slides were mounted with Gelvatol containing DABCO $0.1 \mathrm{~g} / \mathrm{mL}$ (SigmaAldrich, Diegem, Belgium).

Primary antibodies for immunofluorescence were mouse monoclonal anti-neurofilament (NF; clone SMI32, NE1023, dilution 1:1000; Millipore, Overijse, Belgium), rabbit monoclonal anti-synaptophysin (\#01-1019, dilution 1:500, Millipore) and rabbit polyclonal anti-human tau (BR21, dilution 1:500). ${ }^{12}$ Secondary antibodies were a goat antimouse antibody conjugated to fluorescein isothiocyanate (F-1010, dilution 1:250; Sigma-Aldrich) or a goat antirabbit antibody conjugated to biotin (BA-1000, 1:300; Vector Laboratories, Burlingame, CA) followed by streptavidin conjugated to AlexaFluor 488 (S-11223, dilution 1:250; Life Technologies, Merelbeke, Belgium). BTX conjugated to Alexa594 (B13423, dilution 1:1000; Life Technologies) was incubated with the secondary antibodies. Pictures were taken with an Axiovert 200M fluorescence microscope (Carl Zeiss, Zaventem, Belgium). For all images, brightness and contrast were adjusted with Adobe Photoshop CS3 extended version 10.0 (Adobe Systems, San Jose, CA) after acquisition to match with the observation.

\section{Analysis of the Maturation and the Innervation Status of Motor Endplates}

Motor endplate maturation was evaluated in postnatal day (P)14 newborn mice based on criteria previously described. ${ }^{13,14}$ A minimum of 100 junctions was analyzed for each animal $(n=3)$. The innervation status of motor endplates was assessed after labeling with the synaptophysin antibody and BTX by classifying the synaptophysin distribution into three categories: i) perfect superposition of 
the BTX and synaptophysin labeling; ii) partial superposition of synaptophysin and BTX labeling; and iii) absence of synaptophysin labeling. ${ }^{15}$ The innervation status of NMJ was also assessed after labeling with NF and BTX by categorizing them as innervated if there was any overlap between the two labels or denervated if NF was completely absent at the synaptic junction. ${ }^{16} \mathrm{~A}$ minimum of 300 junctions was analyzed for each mouse $(n=3)$.

\section{Immunocytochemistry}

The immunohistochemical labeling was performed using the ABC method. Briefly, tissue sections were treated with peroxide for 30 minutes to inhibit endogenous peroxidase. After washes in Tris buffer saline (TBS), sections were incubated with the blocking solution (10\% horse serum or goat serum in TBS $/ 0.13 \%$ sodium azide). The primary antibodies were diluted in $1 \%$ horse serum or goat serum/TBS/0.13\% $\mathrm{NaN}_{3}$ and incubated on tissue sections overnight at room temperature. After washes in TBS, sections were sequentially incubated with either horse anti-mouse or goat anti-rabbit antibodies conjugated to biotin (Vector Laboratories) for 30 minutes at room temperature, followed by the $\mathrm{ABC}$ complex (Vector Laboratories). After washes in TBS, the peroxidase activity was detected using diaminobenzidine as chromogene (Dako, Carpinteria, CA). In some case, the slides were counterstained with hematoxylin and eosin (H\&E). The slides were mounted with Depex (VWR International).

The primary antibodies for immunocytochemistry were mouse monoclonal anti-NeuN (NEUN-A60, dilution 1:10,000; Millipore), rabbit polyclonal anti-human tau (BR21, dilution 1:5000), ${ }^{12}$ and rabbit polyclonal anticathepsin (BR6, dilution 1:5000). ${ }^{17}$

\section{Gallyas Staining}

Gallyas staining was used for the detection of tau aggregates. Formalin-fixed, paraffin-embedded sections of the sciatic nerve ( $7 \mu \mathrm{m}$ thick) from 7- and 10-month-old WT and Tg30 mice were stained with a modified Gallyas silver-staining method $^{10,18}$ and counterstained with $0.1 \%$ Nuclear Fast Red.

\section{Motor Neuron Counts}

The number of motoneurons in lumbar spinal cord sections was quantified after staining with cresyl violet stain and after immunohistochemistry for NeuN. Counting of motoneurons was performed on the left and right ventral sides of three spinal cord sections for each mouse $(n=3)$. Motoneurons were identified on the basis of the large size of their cell body and the cytoplasmic abundance of Nissl bodies.

\section{Fiber Diameter Analysis}

A fragment of hindlimb muscle was dissected at 1 month and the tibialis anterior, gastrocnemius, and quadriceps

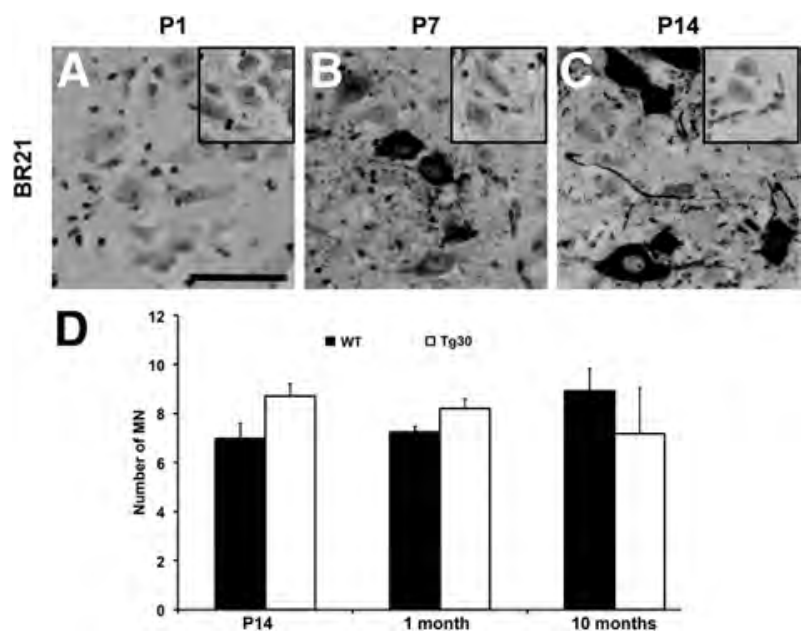

Figure 1 Human tau transgenic protein is expressed in the spinal cord of Tg30 mice from P7. A-C: Immunocytochemical labeling with the BR21 antibody specific for human tau on traverse sections of the lumbar spinal cord (anterior horn) of Tg30 mice at P1 (A), P7 (B), and P14 (C). Insets show the immunolabelling with the BR21 antibody on traverse sections of the lumbar spinal cord of WT mice. A: Human tau transgenic protein is not expressed in the lumbar spinal cord of Tg30 mice at P1. B and C: Human tau transgenic protein is expressed in motoneurons of the anterior horn in the lumbar spinal cord of Tg30 mice from P7. D: Quantification of motor neuron numbers in the lumbar spinal cord of WT (black bars) or Tg30 (white bars) at P14, 1 month, or 10 months. The number of motor neurons is similar in WT and in Tg30 mice. No significance was observed with the $t$-test. Error bars indicate means \pm SEM. $n=3$ (D). Scale bar $=50 \mu \mathrm{m}$. BR21, human-specific antibody to tau; MN, motor neuron; P, postnatal day; WT, wild type.

muscles were dissected at 3 and 10 months. They were formalin-fixed, paraffin-embedded, cut (7 $\mu \mathrm{m}$ thick), and stained with H\&E. Pictures were acquired with a DM5000 microscope with LAS EZ software version 3.0 (Leica Microsystems). The muscle fiber cross-sectional area (CSA) was measured on 200 fibers for quadriceps and gastrocnemius muscles and on 100 fibers for tibialis and hindlimb muscles of mice, age 1 month, in each animal $(n=3)$ using the ImageJ software version 1.49s $(\mathrm{NIH}$, Bethesda, MD; http://imagej.nih.gov/ij).

\section{Electromyography}

Electromyography recordings were performed in control and $\operatorname{Tg} 30$ mice ages 2 months to 11 months; measurements were conducted at $2(n=4), 3(n=4), 6(n=5), 8$ $(n=3)$ and $11(n=4)$ months of age. Repeated measurements were obtained at 1-month intervals for four mice and at 5-month intervals for four other mice. The animals were first sedated by intraperitoneal injection of $1 \mu \mathrm{g} / \mathrm{g}$ body weight of medetomidine (Sedator; Eurovet Animal Health, Bladel, the Netherlands). Anesthesia was induced and maintained using isoflurane (Isoflo, $1.5 \%$ in oxygen; Abbott Laboratories, Wavre, Belgium) delivered through a face mask $(0.4 \mathrm{~mL}$ per minute). The sedation was reverted by intraperitoneal injection of $0.25 \mu \mathrm{g}$ of atipamezol (Antisedan; Elanco, Anvers, Belgium). During the anesthesia, the 

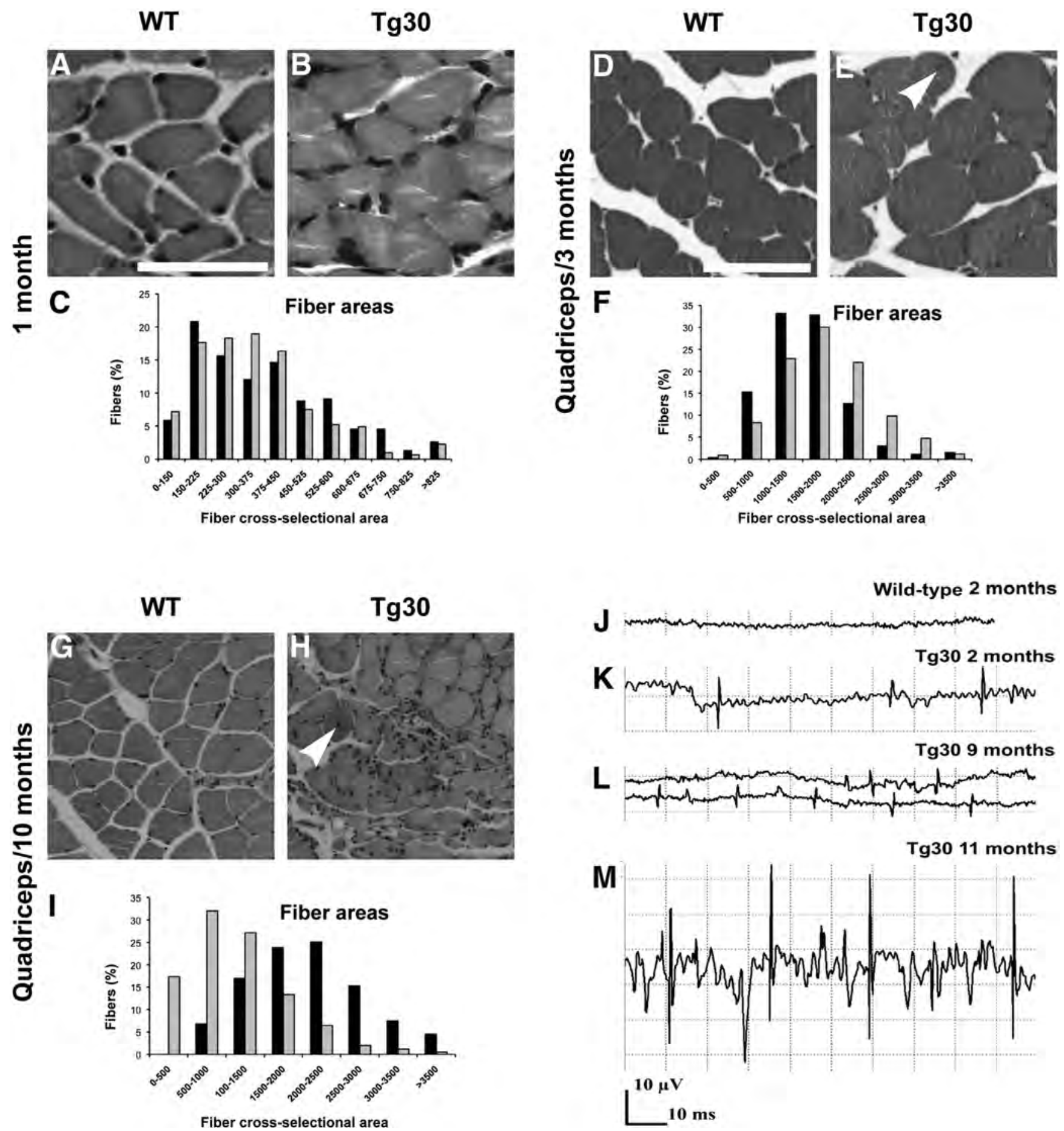

Figure 2 Early muscle hypertrophy and late hypotrophy in mutant tau $\mathrm{Tg} 30$ mice. A and B: H\&E staining of transverse sections of hindlimb muscles from 1-month-old WT (A) or Tg30 (B), showing a similar aspect in both groups. C: Distribution of muscle fiber cross-sectional areas in hindlimb muscles of 1-monthold WT (black bars) or Tg30 (gray bars) mice. The distribution of fiber areas in posterior muscle is similar in WT and in Tg30 mice at 1 month. D and E: H\&E staining of transverse sections of quadriceps muscle from 3-month-old WT (D) or Tg30 mice (E). Some signs of muscle degeneration are observed in Tg30 mice as shown by the presence of nuclei in the center of muscle fibers (arrowhead) and of clusters of fibers with reduced size. Numerous fibers in Tg30 mice have a large size. F: Distribution of muscle fiber cross-sectional areas in quadriceps muscle of 3-month-old WT or Tg30 mice. The distribution of fiber areas in quadriceps muscle indicates that there is a significantly increased proportion of the largest muscle fibers in Tg30 mice at 3 months. $\mathbf{G}$ and $\mathbf{H}: \mathrm{H} \& \mathbf{E}$ staining of transverse sections of quadriceps muscle from 10-month-old WT (G) or Tg30 (H) mice. There is a reduction in cross-sectional areas of many muscle fibers and frequent nuclei are located in the center of muscle fibers (arrowhead), indicative of muscle degeneration. I: Distribution of muscle fiber areas in quadriceps muscle of 10-month-old WT or Tg30 mice. There is a significantly increased proportion of the smallest muscle fibers in Tg30 mice at 10 months. J-M: Electromyogram recordings of gastrocnemius muscle in $W T(\mathbf{J})$ or $\operatorname{Tg} 30(\mathbf{K}-\mathbf{M})$ mice aged $2(\mathbf{J}$ and $\mathbf{K}), 9(\mathbf{L})$, and 11 (M) months. The number of spontaneous muscle activities has a net tendency to increase with aging in Tg30 mice. $n=3(\mathbf{F}$ and $\mathbf{I}) . P<0.001$ by $\chi^{2}$ Pearson's test [comparison of 1 month $(\mathbf{C})$ with 3 months (F), and 10 months (I) with 1 month (C)]. Scale bars: $50 \mu \mathrm{m}(\mathbf{A}$ and $\mathbf{D})$. H\&E, hematoxylin and eosin; WT, wild type. 
animals were placed on a heated pad $\left(38^{\circ} \mathrm{C}\right)$. A Medelec Sierra II apparatus (Medelec Instruments, New Delhi, India) connected to a personal computer running the program Sierra XP version 3.3.3 was used for both stimulation and recordings. The stimulation of the sciatic nerve was performed using percutaneous needle electrodes placed caudal to the greater trochanter, close to the sciatic nerve. Recordings were documented using subcutaneous needle electrodes inserted at the level of the gastrocnemius muscle in a belly-tendon configuration; a subcutaneous ground electrode was positioned midway between the stimulating cathode and the recording electrode. The maximum amplitude of the muscle compound action potential was recorded, and its decrement during a train of 10 stimulations at 3 per second was measured (calculated as the difference between the amplitude of the tenth and first response divided by the amplitude of the first response). Detection electromyography was performed with concentric needle electrode $(25 \times 0.3 \mathrm{~mm}$; Technomed, Maastricht, the Netherlands) inserted in the leg muscles at least at three locations, and spontaneous muscle activities were recorded. The amplitudes of the muscle potential evoked by the sciatic nerve stimulation were compared using a $t$-test for paired samples in the $2 \times 4$ mice groups.
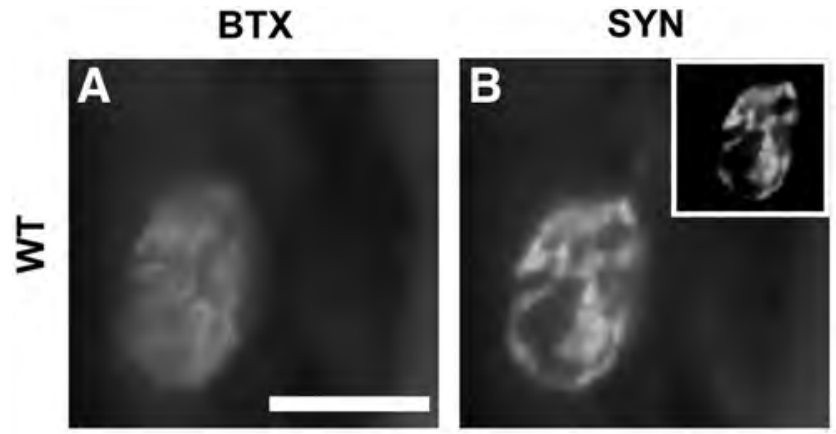

E
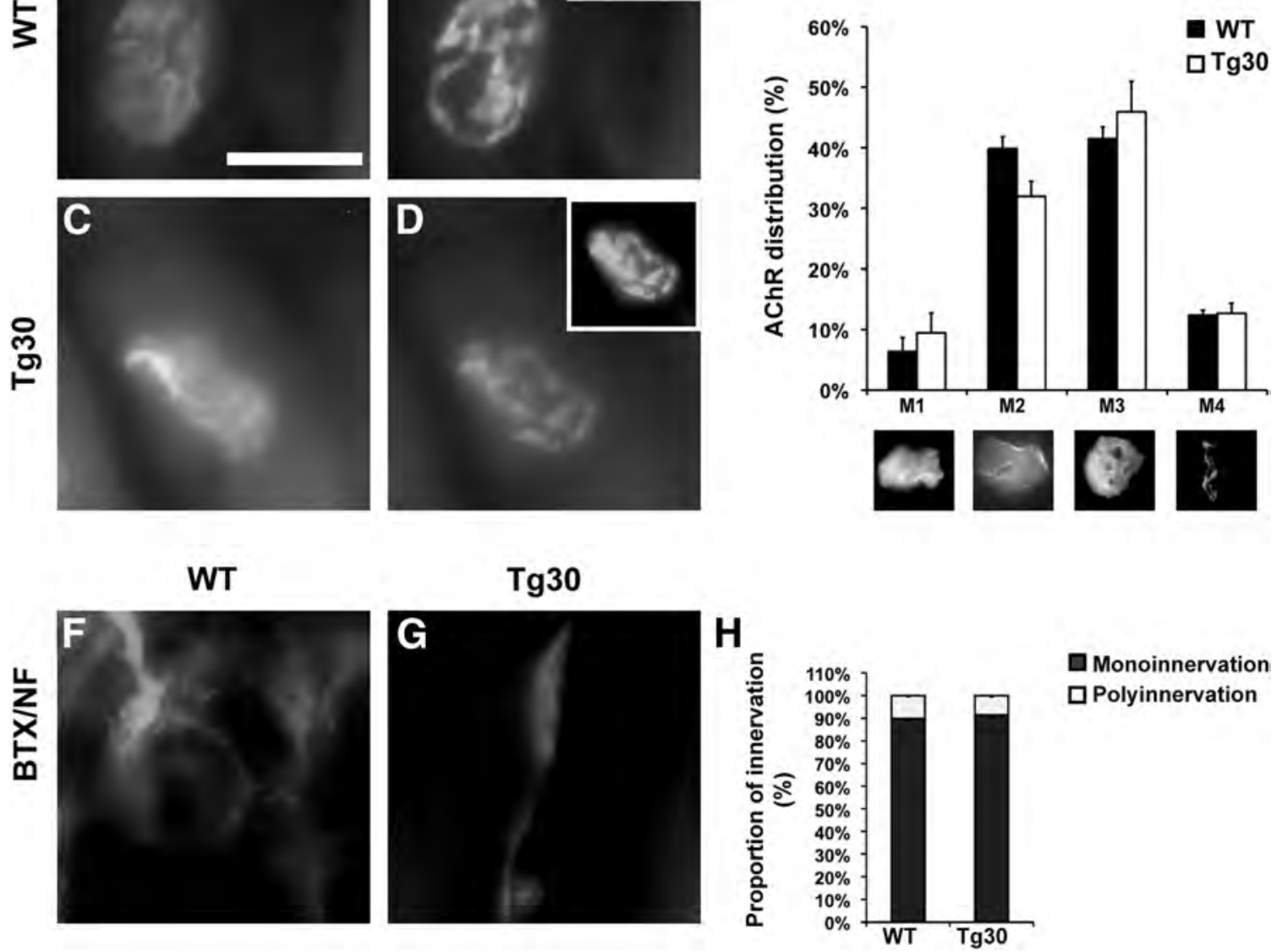

Figure 3 The initial formation of NMJ and their innervation is not disrupted in Tg30 mice. A-D: Double labelling on muscle fiber sections of acetylcholine receptors in muscle motor endplate by $\boldsymbol{\alpha}$-bungarotoxin $(\mathbf{A}$ and $\mathbf{C})$ and immunofluorescence detection of synaptophysin in motor nerve terminal $(\mathbf{B}$ and $\mathbf{D})$ in WT (A and B) or Tg30 (C and D) mice at P14. Insets in B and D show overlapping BTX/SYN labelling illustrated in A and B, and C and D, respectively. The progressively increased apposition of the motor nerve terminals to motor endplates observed during the maturation of the motor endplates happens normally in Tg30 mice. E: Quantification of NMJ maturation in WT or Tg30 mice at P14 based on four morphological stages of AChR patterns of distribution (M1: oval plaque; M2: single perforation; M3: multiple perforations; M4: mature junction). The proportion of each stage is similar in WT and Tg30 mice, indicating that the maturation of the NMJ junctions is normal in Tg30 mice. Error bars indicated means \pm SEM. $\mathbf{F}$ and $\mathbf{G}$ : Labeling of acetylcholine receptors by $\alpha$-bungarotoxin and immunofluorescence detection of neurofilament on muscle fiber sections of WT (F) and $\operatorname{Tg} 30$ (G) mice at P14. The innervation of motor endplates is normal in Tg30 mice. H: Quantification of muscle mono- or polyinnervation at P14 using NF/BTX overlap as criterion. The proportion of mono- or polyinnervated endplates is similar in WT and Tg30 mice. The $t$-test showed nonsignificant results. $n=3$ (E and $\mathbf{H}$, each group). Scale bar $=5 \mu \mathrm{m}$. AChR, acetylcholine receptor; BTX, $\alpha$-bungarotoxin; NF, neurofilament; NMJ, neuromuscular junctions; P, postnatal day; SYN, synaptophysin; WT, wild type. 


\section{1 month}
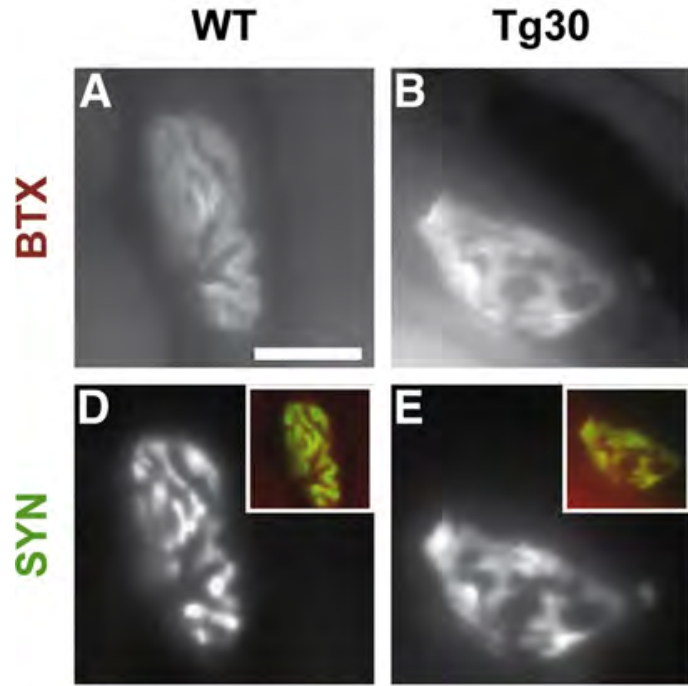

$\operatorname{Tg} 30$
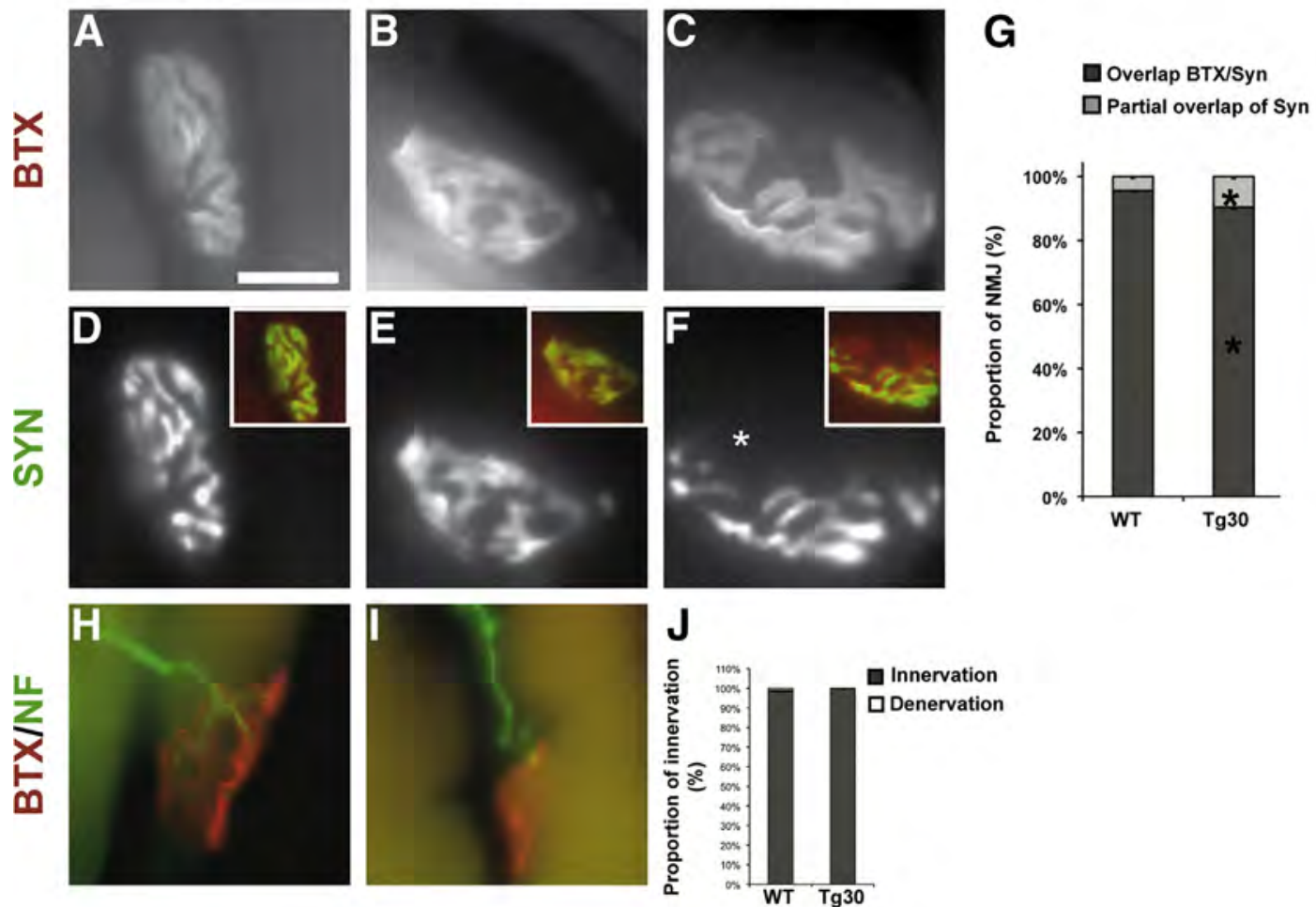

10 months
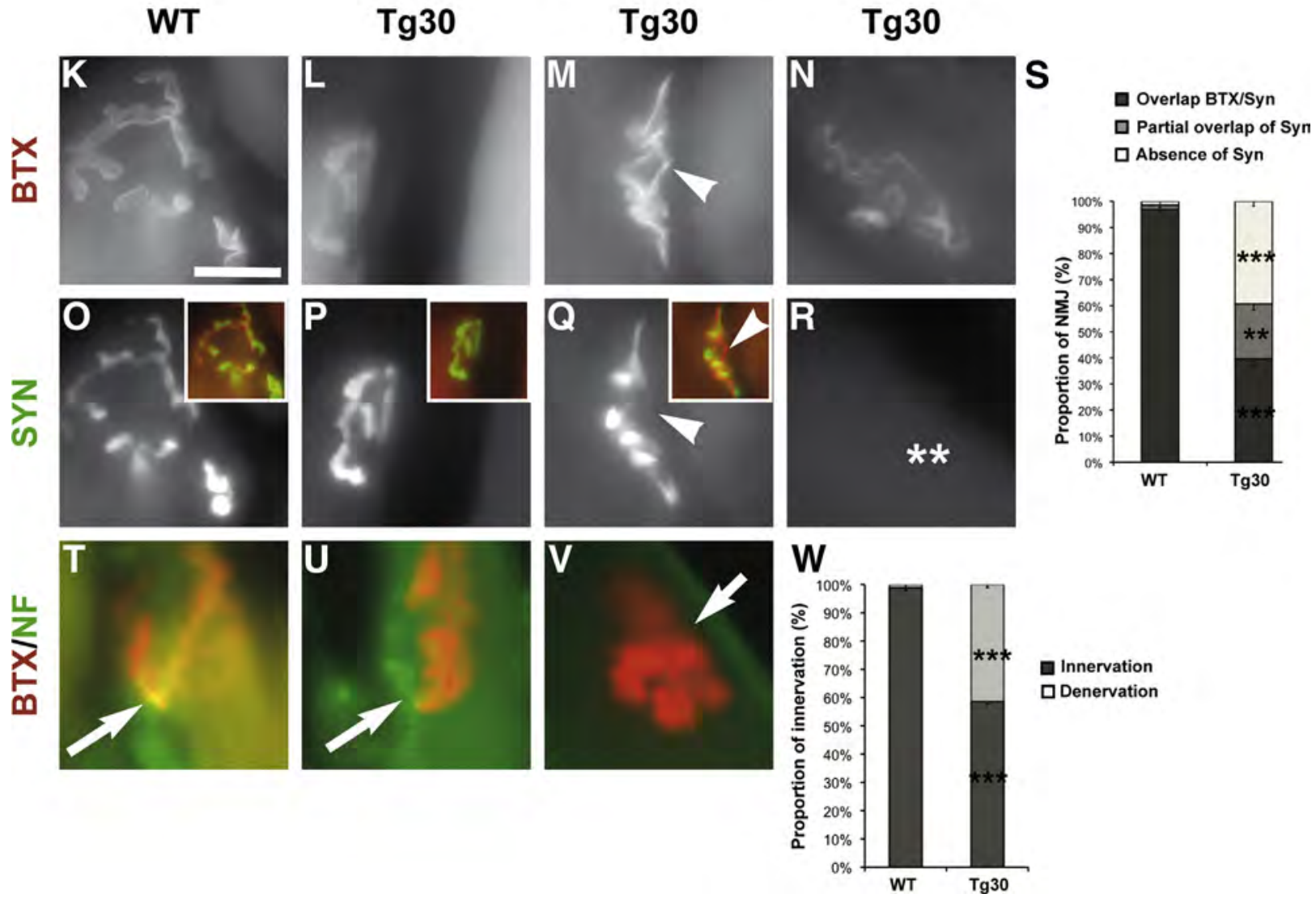


\section{Statistics}

Data are presented as means \pm SEM. Unpaired $t$-test and $\chi^{2}$ Pearson's test were used to determine statistical significance using GraphPad Prism version 4 software (San Diego, CA). Differences at $P<0.05$ were considered significant.

\section{Results}

\section{Human Tau Transgenic Protein Is Expressed in the Spinal Cord of Tg30 Mice from P7}

To determine the timing of postnatal expression of human tau transgenic protein, an immunocytochemical labeling with the BR21 antibody specific for human tau was performed on traverse sections of the lumbar spinal cord of Tg30 and WT mice at P1, P7, and P14. At P1, the human tau transgenic protein was not detected in the spinal cord of Tg30 newborn mice (Figure 1A) but was detected at P7 in the cell bodies and in some axonal processes in motoneurons of the ventral horn of $\mathrm{Tg} 30$ mice (Figure 1B). The expression of human tau was increased in $\mathrm{Tg} 30$ mice at $\mathrm{P} 14$, and the protein was clearly detected in neuronal processes (Figure 1C). Human tau protein was also detected from P7 in the brain of $\operatorname{Tg} 30$ mice (data not shown). Thus, human tau transgenic protein was expressed early in motoneurons of the ventral horn in the spinal cord and in the brain from $\mathrm{P} 7$ in $\mathrm{Tg} 30$ newborn mice.

\section{Tg30 Mice Show an Early Hypertrophy of Muscle Fibers and a Late Hypotrophy of Muscle Fibers}

Tg30 mice develop a motor deficit of hindlimbs from 8 months of age that is severely worsened at 12 months. ${ }^{10}$ To analyze the evolution of muscular atrophy, the mean CSA of muscle fibers in hindlimb muscles was measured at 1, 3, and 10 months in $\mathrm{Tg} 30$ mice. The mean CSA and the distribution of muscle fibers areas were similar in WT and $\operatorname{Tg} 30$ mice at 1 month (Figure 2, A-C). By contrast, at 3 months, the CSA in quadriceps muscle (Figure 2, D-F) and gastrocnemius muscle (data not shown) increased in $\mathrm{Tg} 30$ mice and was associated with a significantly increased proportion of muscle fibers with large sizes (Figure 2F). At 3 months, the CSA in tibialis muscle was similar in WT and Tg30 mice (data not shown). Furthermore, nuclei in the center of muscle fibers were frequently observed in $\mathrm{Tg} 30$ mice at 3 months, suggesting that $\mathrm{Tg} 30$ muscle fibers undergo degeneration (Figure 2, D-F). At 10 months, the CSA in gastrocnemius, quadriceps, and tibialis muscles was decreased in $\operatorname{Tg} 30$ mice and was associated with a significantly increased proportion of muscle fibers with small sizes (Figure 2I). In addition, muscle fibers with central nuclei were frequently observed in Tg30 mice at 10 months (Figure 2, G-I).

Thus, at 3 months, Tg30 mice showed an increased proportion of hypertrophic muscle fibers in gastrocnemius and quadriceps muscles associated with the beginning of muscle fiber degeneration. Whereas at 10 months, Tg30 mice showed an increased proportion of hypotrophic muscle fibers with robust signs of muscle fiber degeneration.

\section{Absence of Motoneuron Loss in the Spinal Cord of Tg30 Mice}

To rule out the possibility that muscle atrophy in $\operatorname{Tg} 30$ mice could be the consequence of a denervation due to neuronal loss in the spinal cord, the number of motoneurons was evaluated in the lumbar spinal cord of WT and Tg30 mice at different ages (P1, P7, P14, 1, 3, and 10 months). The density of lumbar motoneurons was similar in WT and Tg30 mice at all investigated ages (Figure 1D). These results

\footnotetext{
Figure 4 Expression of human tau transgenic protein leads to NMJ denervation in adult Tg30 mice. A-F: Labeling of acetylcholine receptors by a-bungarotoxin (red, A-C) and immunofluorescence labeling of synaptophysin (green, D-F) on muscle fiber sections of 1-month-old WT (A and D) or Tg30 (B, C, $\mathbf{E}$, and $\mathbf{F}$ ) mice. Insets in $\mathbf{D}, \mathbf{E}$, and $\mathbf{F}$ show overlapping BTX/SYN labeling illustrated in $\mathbf{A}$ and $\mathbf{D}, \mathbf{B}$ and $\mathbf{E}$, and $\mathbf{C}$ and $\mathbf{F}$, respectively. $\mathbf{A}$ and $\mathbf{D}$ : In WT mice, NMJ display the expected pretzel-like shape and show perfect apposition of the synaptophysin labeling with the motor endplate. B and E: In Tg30 mice, a majority of NMJ are very similar to those observed in WT animals. C and F: In 1-month-old Tg30 mice, a minority of NMJ junctions show a defective localization of synaptophysin, which only partially overlaps with AChR labeling (the asterisk in $\mathbf{F}$ shows an area of a motor endplate devoid of overlapping synaptophysin labeling). G: Quantification of patterns of synaptophysin distribution in NMJ of WT or Tg30 mice at 1 month. Both in WT and in Tg30 mice, the vast majority of NMJ shows a perfect superposition of synaptophysin and $\alpha$-bungarotoxin labelling (black), and a minority shows a partial overlap (gray) $\mathbf{H}$ and I: Labeling of acetylcholine receptors by $\alpha$-bungarotoxin (red) and immunofluorescence detection of neurofilament (green) on muscle fiber sections of 1-month-old WT (H) or Tg30 (I) mice. All of the junctions were innervated in Tg30 mice. J: Quantification of muscle innervation at 1 month in WT and Tg30 mice using NF/BTX overlap as criterion. The vast majority of junctions are innervated in both WT and Tg30 mice. $\mathbf{K}-\mathbf{R}$ : Labeling of acetylcholine receptors by $\alpha$-bungarotoxin (red, $\mathbf{K}-\mathbf{N}$ ) and immunofluorescence labeling of synaptophysin (green, $\mathbf{0}-\mathbf{R}$ ) on muscle fibers section of 10 -month-old WT (K and $\mathbf{0}$ ) or Tg30 ( $\mathbf{L}-\mathbf{R}$ ) mice. Insets in $\mathbf{0}$, $\mathbf{P}$, and $\mathbf{Q}$ show overlapping BTX/SYN labeling illustrated in $\mathbf{K}$ and $\mathbf{0}, \mathbf{L}$ and $\mathbf{P}$, and $\mathbf{M}$ and $\mathbf{Q}$, respectively. $\mathbf{K}$ and $\mathbf{0}$ : In WT mice, NMJ display the expected pretzel-like shape and show perfect apposition of the synaptophysin labeling to the motor endplate. $\mathbf{L}$ and $\mathbf{P}: \mathbf{I n}$ Tg30 mice, a minority of NMJ are very similar to those observed in WT animals. M, N, Q and R: A majority of junctions in Tg30 mice show defective localization of synaptophysin, which only partially overlaps with AChR labeling ( $\mathbf{M}$ and $\mathbf{Q}$, arrowhead) or is absent ( $\mathbf{N}$ and $\mathbf{R}$, double asterisks). S: Quantification of synaptophysin distribution in NMJ of WT or Tg30 at 10 months. Synaptophysin labeling is properly superposed to the $\alpha$-bungarotoxin labeling in a vast majority of junctions in WT mice (black), but only in a minority of NMJ in Tg30 mice, and shows most often a partial overlap (gray), or is absent from the terminal nerve (white). T-V: Labeling of acetylcholine receptors by $\alpha$-bungarotoxin (red) and immunofluorescence labeling of neurofilament (green) on muscle fiber sections of 10-month-old WT (T) or Tg30 (U and V) mice. T: All of the junctions are innervated in WT mice. U: Some junctions are innervated in Tg30 mice, but others are denervated (V). Arrows point on the juunctions (T-V). W: Quantification of muscle innervation at 10 months in WT and Tg30 mice using NF/BTX overlap as criterion. The vast majority of junctions are innervated in WT mice (black), but a significant proportion are denervated (gray) in Tg30 mice. ${ }^{*} P<0.05(\mathbf{G}),{ }^{* *} P<0.01(\mathbf{S})$, and ${ }^{* * *} P<0.001(\mathbf{S}$ and $\mathbf{W})$ by $t$-test. $n=3(\mathbf{J}, \mathbf{S}$, and $\mathbf{W}$ ). Scale bars: $5 \mu \mathrm{m}$ (A and K). BTX, $\alpha$-bungarotoxin; NF, neurofilament; NMJ, neuromuscular junctions; SYN, synaptophysin; WT, wild type.
} 

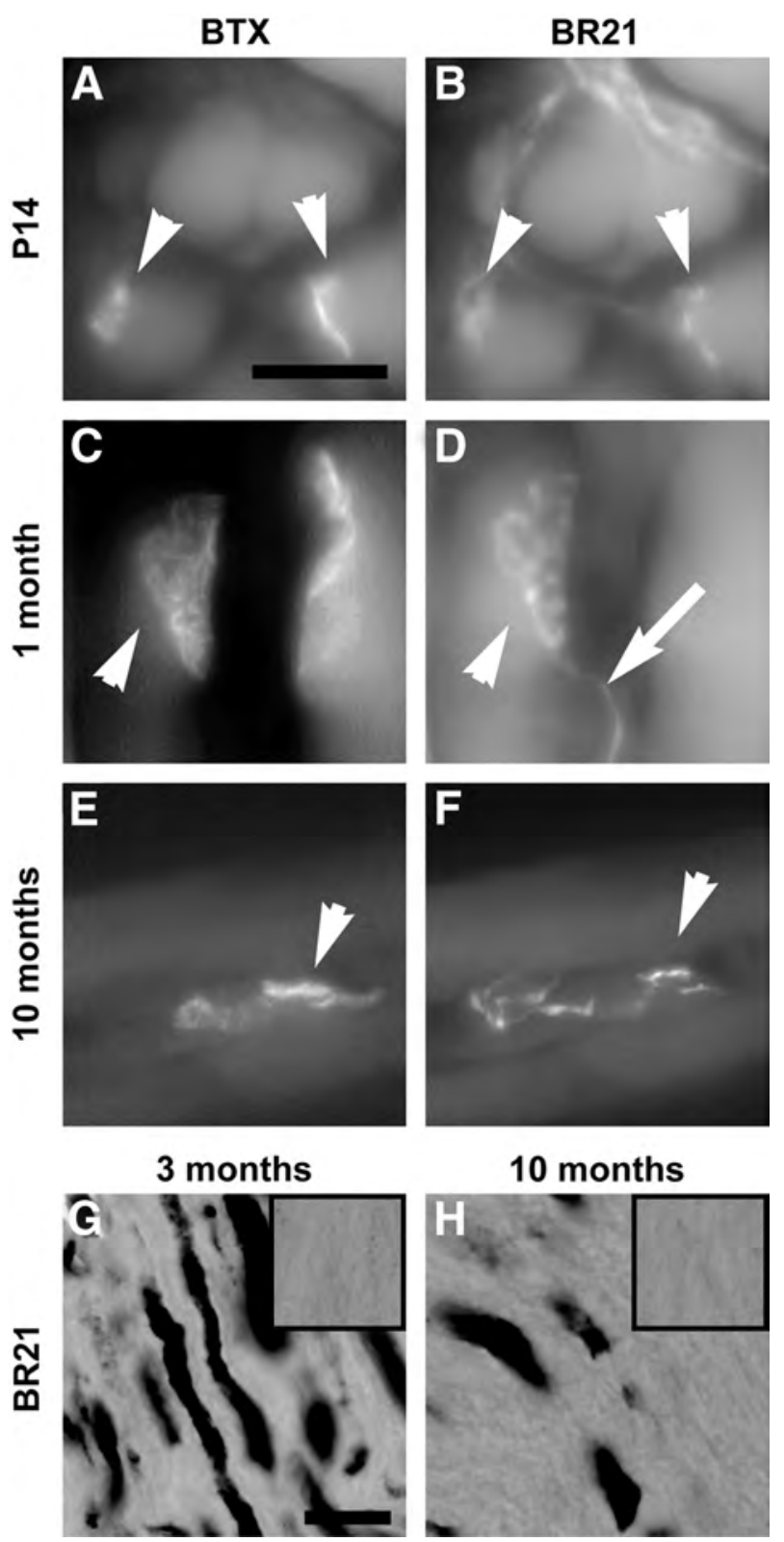

Figure 5 Human tau transgene is expressed in sciatic nerve and in the motor nerve terminals. A-F: Labeling of acetylcholine receptors by $\alpha$-bungarotoxin $(\mathbf{A}, \mathbf{C}$, and $\mathbf{E})$ and immunofluorescent labeling of human tau transgenic protein with the BR21 antibody $(\mathbf{B}, \mathbf{D}$, and $\mathbf{F})$ on muscle fiber sections of P14 (A and B), 1-month-old (C and D), or 10-month-old (E and F) Tg30 mice. Human tau is detected in the motor nerve terminals (arrowheads) and in axons (arrows) from P14 and its distribution overlaps to some extent with BTX labeling in the motor endplate. $\mathbf{G}$ and $\mathbf{H}$ : Immunocytochemical labeling of human tau with the BR21 antibody on longitudinal sections of the sciatic nerve of Tg30 mice at 3 months $(\mathbf{G})$ and 10 months $(\mathbf{H})$. Insets show results of a similar labeling with the BR21 antibody on longitudinal sections of sciatic nerves of WT mice ( $\mathbf{G}$ and $\mathbf{H}$ ). Human tau is expressed in axons in the sciatic nerves at 3 months and 10 months. Scale bars: $5 \mu \mathrm{m}(\mathbf{A}-\mathbf{F})$ or $10 \mu \mathrm{m}(\mathbf{G}$ and $\mathbf{H})$. BTX, $\alpha$-bungarotoxin; P, postnatal day; WT, wild type.

confirm our previous observation of absence of neuronal loss in 12-month-old $\mathrm{Tg} 30$ mice $^{10}$ and indicated that the muscular atrophy and the motor deficit in Tg30 mice cannot be simply due to neuronal loss.
The Formation and the Maturation of Neuromuscular Junctions Are Not Affected in Tg30 Mice

We next investigated the formation and the maturation of NMJ in WT and Tg30 mice. The development of NMJ was studied between birth and P14, using BTX as a marker of acetylcholine receptors (AChR) in muscle motor endplates and immunolabelling for synaptophysin to detect synaptic vesicles in motor nerve terminals. The development of NMJ was normal in Tg30 hindlimb muscles. Indeed, at birth, AChR appeared as plaques overlaid with sparse dots of synaptophysin-positive clusters likely corresponding to presynaptic vesicles (data not shown). At P7, motor endplates reorganized and started to display classical perforations whereas morphological matching between motor nerve terminals and motor endplates increased (data not shown). At P14, the most mature junctions displayed a pretzel-like shape, whereas synaptophysin labeling was superposed to the motor endplates, indicative of a precise apposition of the motor nerve terminals to the motor endplates (Figure 3, A-D). To confirm this result, the maturation of NMJ was evaluated at P14 based on four morphological stages of maturation of motor endplates (based on AChR patterns) (Figure 3E) and their innervation status (based on neurofilament immunoreactivity) (Figure 3, F and G). A similar distribution of NMJ maturation stages (Figure 3E) and a similar proportion of monoinnervated motor endplates (Figure $3 \mathrm{H}$ ) was observed in WT and Tg30 mice (Figure 3, F-H). Taken together, these observations suggested that the formation and initial maturation of NMJ were not altered in hindlimb muscles of $\operatorname{Tg} 30$ mice.

\section{Tg30 Mice Develop a Progressive Denervation of Neuromuscular Junctions with Aging and Show an Abnormal Muscle Electrical Activity}

To determine whether more tardive consequences on the stabilization of NMJ might be present in $\mathrm{Tg} 30$ mice, the morphology of NMJ was studied at 1 and 10 months in WT and $\operatorname{Tg} 30$ mice. Labeling of AChR by $\alpha$-BTX unveiled that NMJ displayed a pretzel-like shape in WT and $\mathrm{Tg} 30$ mice at 1 month, indicative of a normal morphology of motor endplates on muscle fibers (Figure 4, A, B, D, E). However, the localization of synaptophysin was defective in a proportion of NMJ in 1-month-old Tg30 mice (Figure 4, C and F). In WT mice, $95.58 \% \pm 0.49 \%$ of the NMJ showed extensive superposition of BTX and of synaptophysin labeling (Figure 4, D and G), indicative of precise apposition between motor nerve terminals and motor endplates. By contrast, in $\mathrm{Tg} 30$ mice, $90.36 \% \pm 0.65 \%$ of NMJ exhibited precise superposition of BTX and of synaptophysin labeling (Figure 4, E and G), and in $9.63 \pm 0.65 \%$ cases, synaptophysin was partly superposed to the BTX labeling (Figure 4, F and G). Despite this defect of synaptophysin distribution at 1 month, the motor endplates were correctly innervated 


\section{7 months}
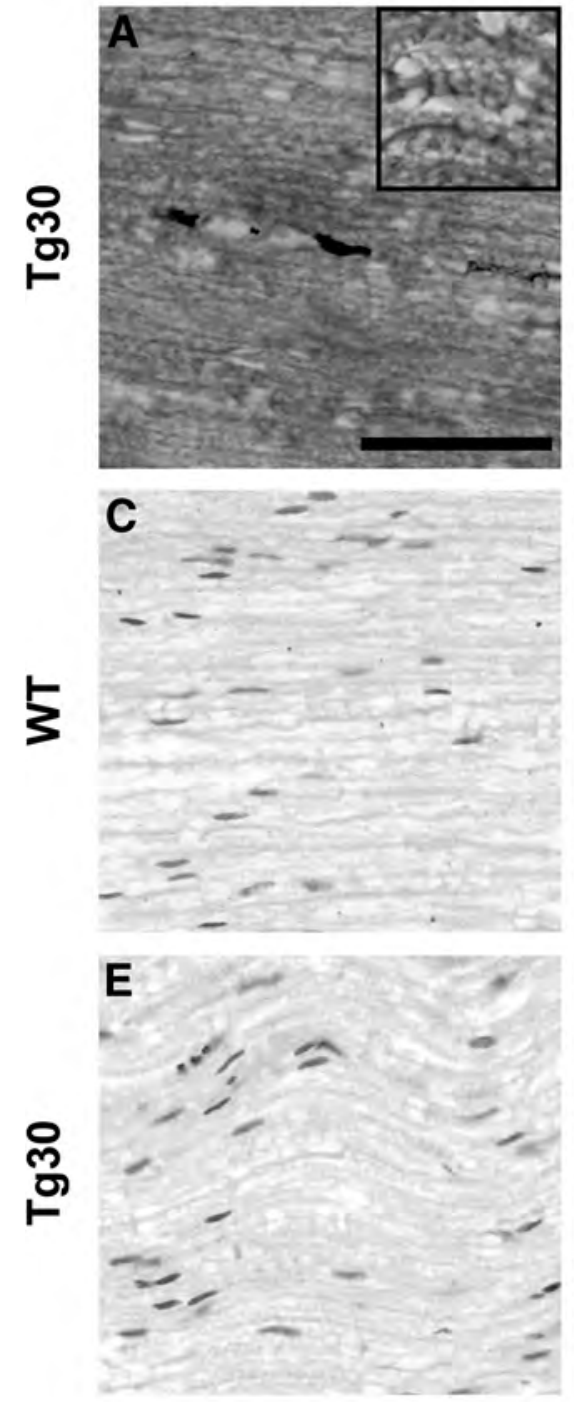

7 months
10 months
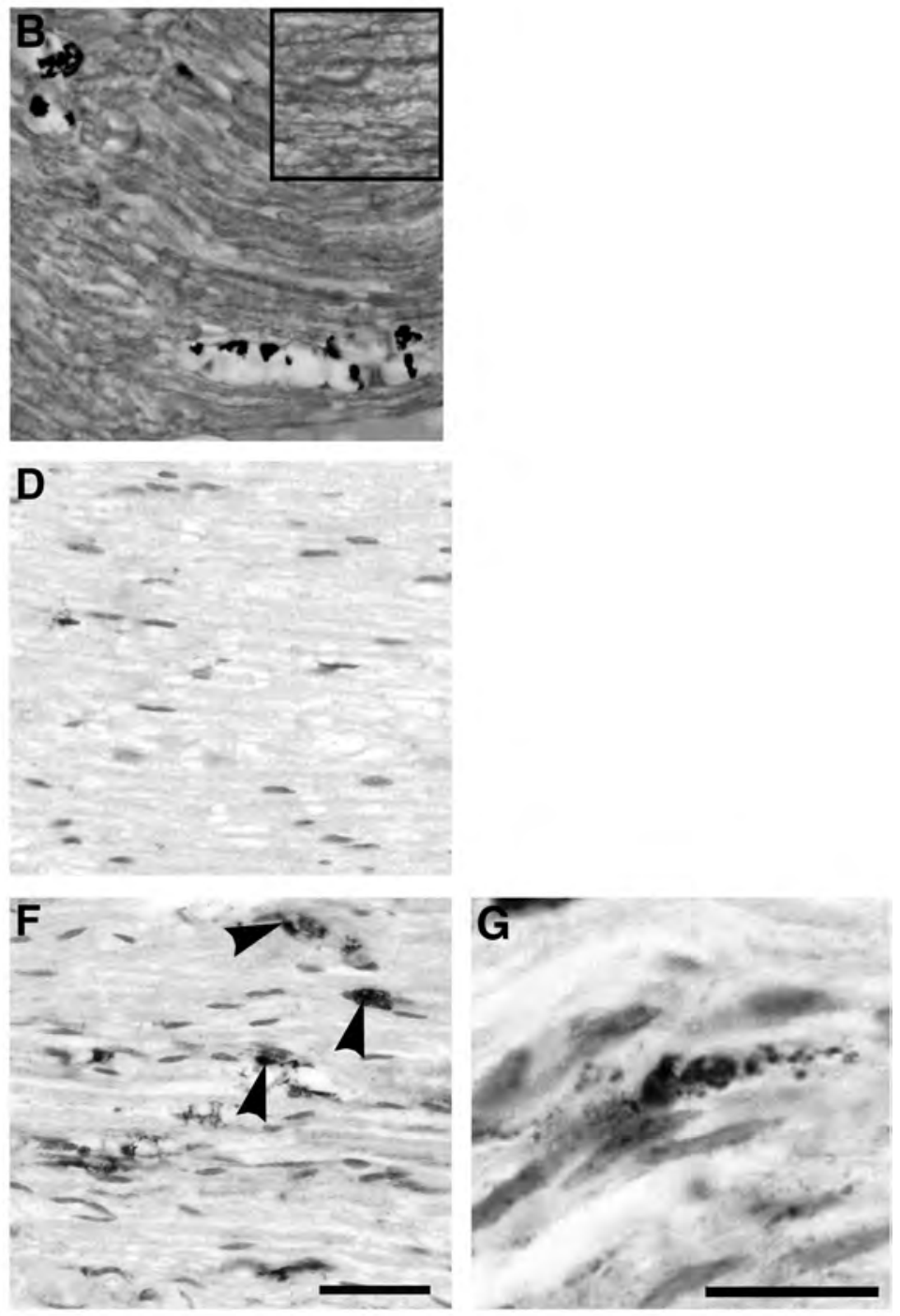

10 months

Figure 6 Human tau expression leads to accumulation of Gallyas-positive inclusions and cathepsin B-positive vesicular clusters in sciatic nerve. A and B: Gallyas silver staining of longitudinal sections of sciatic nerve of Tg30 mice at 7 (A) and 10 (B) months counterstained with Nuclear Fast Red. Insets show the same staining on longitudinal sections of sciatic nerve of WT mice. Gallyas-positive aggregates are observed in Tg30 mice at 7 months and 10 months. C-G: Immunocytochemical labeling with the BR6 antibody to cathepsin B on longitudinal sections of the sciatic nerve of WT (C and $\mathbf{D})$ or Tg30 (E- $\mathbf{G})$ mice at 7 months ( $\mathbf{C}$ and $\mathbf{E}$ ) and 10 months (D, F, and $\mathbf{G})$ counterstained with hematoxylin and eosin. The distribution of cathepsin B-positive vesicular structures is similar at 7 months in WT and Tg30 mice. Local accumulations of clusters of cathepsin B-positive vesicular structures (arrowheads) are observed in the sciatic nerves of Tg30 mice at 10 months. Scale bars: $25 \mu \mathrm{m}$ (A and $\mathbf{B}) ; 30 \mu \mathrm{m}(\mathbf{C}-\mathbf{F}) ; 10 \mu \mathrm{m}(\mathbf{G})$. WT, wild type.

by motor nerve terminals in $\mathrm{Tg} 30$ mice as judged by NF/ BTX labeling (Figure 4, H-J).

In 10 -month-old WT mice, $96.81 \% \pm 0.41 \%$ of the NMJ showed extensive superposition of BTX and of synaptophysin labeling (Figure 4, K, O, and $\mathrm{S}$ ), indicative of perfect apposition of motor nerve terminals to the motor endplates. By contrast, in $\mathrm{Tg} 30$ mice, only $39.64 \% \pm 3.31 \%$ of NMJ exhibited perfect superposition of motor nerve terminals to the motor endplates (Figure 4, L, P, and S). In the other NMJ, the synaptophysin labeling was either partly superposed to the BTX labeling (Figure 4, M, Q, and S) or absent
(Figure 4, N, R, and S). Furthermore, in WT mice and in a proportion of $\operatorname{Tg} 30$ mice, NMJ were correctly innervated (Figure 4, T, U, and W). But in $41.36 \% \pm 2.28 \%$ of $\mathrm{Tg} 30$ NMJ, motor endplates were denervated without apposition of motor nerve terminals (Figure 4, V and W). Taken together, these data demonstrate a disturbance of NMJ stabilization in $\operatorname{Tg} 30$ mice leading to a progressive denervation of motor endplates with aging.

Furthermore, the denervation of motor endplates observed in $\operatorname{Tg} 30$ mice was confirmed by electromyographic recordings (Figure 2, J-M). Positive sharp waves and/or 


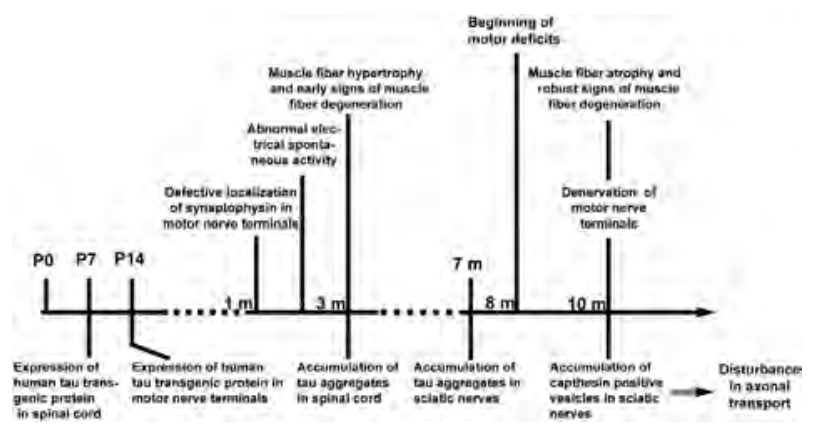

Figure 7 Chronological sequence of pathological events observed in $\mathrm{Tg} 30$ mice. Human tau transgenic protein is expressed in the spinal cord of $\mathrm{Tg} 30$ mice from P7 and in motor nerve terminals from P14. The development of neuromuscular junctions is normal in Tg30 newborn mice, but a defective localization of synaptophysin in motor nerve terminals is observed from 1 month. Then, at 2 months, an abnormal spontaneous electrical activity is detected in hindlimb muscles of $\mathrm{Tg} 30$ mice. At 3 months, accumulation of tau aggregates are observed in the spinal cord of $\mathrm{Tg} 30$ mice. In addition, some muscle fibers are hypertrophic and early signs of muscle fiber degeneration are apparent. At 7 months, accumulation of tau aggregates are observed in sciatic nerves. At 8 months, the beginning of deficit motor is observed in Tg30 mice. Finally, at 10 months, accumulation of cathepsin-positive vesicles are evident in sciatic nerves of $\mathrm{Tg} 30$ mice, suggesting a disturbance of axonal transport. Moreover, muscle fibers of $\operatorname{Tg} 30$ mice are atrophic and exhibit robust signs of degeneration. A severe denervation is also observed at this age. These pathogenic events lead to muscular weakness and a severe motor deficit. P, postnatal day; m, month(s).

fibrillation were detected in some $\operatorname{Tg} 30$ mice at 2 months of age that became more abundant in older animals. At 10 months of age, abundant spontaneous activities could be recorded in $\mathrm{Tg} 30$ mice (Figure $2 \mathrm{M}$ ). Spontaneous activities were not observed in 2-month-old WT mice (Figure 2J). To test whether this abnormal electrical activity reflected an altered neurotransmission at the NMJ, we recorded the muscle evoked response to repetitive nerve stimulation. If neuromuscular transmission was affected, a sharp decrease $(>10 \%)$ in the amplitude of the electrical response should be observed after repeated stimulations. But muscle compound action potential amplitude decrement ranged from $-0.4 \%$ to $-9.9 \%$ in $\mathrm{Tg} 30$ mice, indicating that neuromuscular transmission did not seem compromised using this test.

Human Tau Transgenic Protein Is Expressed in Sciatic Nerve and in Motor Nerve Terminals But Not in Muscle in $\operatorname{Tg} 30$ Mice

We further analyzed the expression and the localization of the human tau protein in the NMJ, sciatic nerve, and muscle of $\mathrm{Tg} 30$ mice. To analyze tau expression in NMJ, we performed a double labeling of AChR by $\alpha$-BTX combined with an immunofluorescent labeling of human tau transgenic protein on hindlimb tissue sections in $\operatorname{Tg} 30$ mice at P7, P14, and 1 and 10 months. At P7, human tau protein was not detected in the NMJ (data not shown). At P14, the human tau protein was expressed in axons and in motor nerve terminals (Figure 5, A and B). A superposition of BTX and of human tau protein was observed to some extent in NMJ. The human tau protein was also expressed in axons and in motor nerve terminals at 1 and 10 months in $\mathrm{Tg} 30$ mice (Figure 5, C-F). We also immunolabelled sections of muscle tissue and of sciatic nerve with the BR21 anti-human tau antibody. The human tau protein was expressed in axons of sciatic nerves of 3- and 10month-old $\mathrm{Tg} 30$ mice (Figure 5, G and $\mathrm{H}$ ). Human tau was not detected in muscle (data not shown).

\section{Accumulation of Gallyas-Positive Inclusions in Sciatic Nerve in Tg30 Mice}

Gallyas-positive tau aggregates develop in the brain and the spinal cord of $\mathrm{Tg} 30$ mice with age. ${ }^{10}$ To assess whether aggregates were also present in sciatic nerves in $\mathrm{Tg} 30$ mice, we stained sciatic nerves with the Gallyas silver-staining method. A few elongated Gallyas-positive inclusions and clusters of dot-like inclusions were detected along axons in sciatic nerves of 7-month-old $\mathrm{Tg} 30$ mice (Figure 6A). Gallyas-positive aggregates were much more numerous in 10-month-old $\mathrm{Tg} 30$ mice and of larger size. Gallyas-positive aggregates were also encountered in focal areas of axonal degeneration (Figure 6B). These Gallyas-positive aggregates were not encountered in WT mice (Figure 6, A and B). Thus, Gallyas-positive aggregates develop also in sciatic nerves and increase with age in $\operatorname{Tg} 30$ mice.

\section{Accumulation of Cathepsin B-Positive Vesicular Clusters in Sciatic Nerve in Tg30 Mice}

Tau proteins regulate the stability of axonal microtubules and the axonal transport, ${ }^{7}$ and abnormal expression of tau could disrupt axonal transports and lead to the observed NMJ denervation in $\operatorname{Tg} 30$ mice. Disturbances in the axoplasmic transport leads to accumulation of cathepsin-positive autophagic vacuoles. ${ }^{19}$ To document potential disturbances in the axoplasmic transport in axons in $\mathrm{Tg} 30$ axons, we compared in WT and Tg30 mice the distribution of cathepsin B immunoreactivity in the sciatic nerve at 3, 7, and 11 months (Figure 6, $\mathrm{C}-\mathrm{G})$. At 3 months of age, the cathepsin B immunoreactivity was similar in WT and Tg30 mice (data not shown). Occasional small clusters of cathepsin B-positive vesicular structures were observed along axons at 7 months in sciatic nerve of Tg30 mice, but not in WT mice (Figure 6, C and E). Numerous clusters of such cathepsin $\mathrm{B}$-positive vesicular structures were observed at 10 months in sciatic nerve of $\mathrm{Tg} 30$ mice (Figure 6, F and G), but not in WT mice (Figure 6D).

\section{Discussion}

We show in this study that the $\mathrm{Tg} 30$ tauopathy murine model develops a muscular degeneration due to a progressive NMJ denervation, leading to a severe motor deficit. This motor deficit is preceded by an early defective localization of synaptophysin in NMJ, spontaneous muscle electrical activity, 
muscle fibers degeneration, and accumulation of tau aggregates in sciatic nerve axons. The sequence of appearance of these pathogenic events is schematically represented in Figure 7.

\section{The Motor Phenotype and NMJ Denervation in $\operatorname{Tg} 30$ Mice Is Not Due to Motoneuron Loss}

We did not observe a loss of spinal motoneurons in $\operatorname{Tg} 30$ mice from P0 to 10 months, extending our previous results showing no neuronal loss in 12-month-old Tg30 mice. ${ }^{10}$ This absence of neuronal loss is striking in view of the severe motor phenotype developed by $\operatorname{Tg} 30$ mice from 8 months and onward, and demonstrates that the muscular atrophy and NMJ denervation in Tg30 mice is not secondary to death of spinal motor neurons. A denervation of the neuromuscular junctions despite an absence of death of spinal motor neurons was also observed in a TDP-43 knockout mice model developing a motor impairment around the age of 60 weeks, a degeneration of large motor axons, grouped atrophy of the skeletal muscle. ${ }^{20}$ These observations indicate that a severe motoneuron phenotype can develop in the absence of significant motoneuron death.

\section{Early Expression of Human Tau Transgenic Protein up to the Nerve Terminals of Motoneurons Is Not Associated with Denervation}

We observed that the human tau protein was expressed in cell body and dendrites of motoneurons in the spinal cord of Tg30 mice from P7. This is consistent with the observation that the Thyl promoter starts to drive expression in neurons at $\mathrm{P}^{21}{ }^{21}$ From P14, the human tau protein was also expressed in motor axons and in motor nerve terminals. We previously reported that the human tau protein was detected at P18 in brain and spinal cord of $\mathrm{Tg} 30$ mice. ${ }^{10}$ Despite this early expression of human mutant tau up to the nerve terminals of motoneurons, the initial maturation of NMJ up to P14 was not affected in $\operatorname{Tg} 30$ mice. The first abnormality that we detected was a defect of synaptophysin distribution in a moderate proportion of NMJ at 1 month that was not associated with morphological signs of denervation and without evidence of motor deficits. These observations suggest that the toxic effect of human tau is a relatively slow process that manifests itself only in mature NMJ and leads to a progressive denervation only in adulthood.

\section{Tg30 Mice Develop a Progressive Muscle Denervation}

We observed a two-phase evolution of muscle fibers changes in Tg30 mice. Although the size of muscle fibers was similar at 1 month in WT and Tg30 mice, a higher proportion of hypertrophic muscle fibers (and some signs of muscle fibers degeneration) was seen at 3 months in $\operatorname{Tg} 30$ mice, followed by a higher proportion of hypotrophic muscle fibers (with robust signs of muscle fiber degeneration) at 10 months. This two-phase evolution most probably corresponds to a slow process of muscular denervation: the onset of muscular degeneration concerns a selected population of muscle fibers but initially this is associated to a compensation mechanism with nearby/neighboring muscle fibers increasing their size. The ongoing denervation then concerns an increasing population of muscle fibers showing hypotrophy. The presence of both hypotrophic and hypertrophic muscle fibers has been observed in other models of progressive neurodegenerative diseases. For example, in aged SOD1G93A mice, the gastrocnemius muscles show severe changes, including a small group of atrophic muscle fibers, centrally placed nuclei, and hypertrophic fibers. ${ }^{22}$

This early compensation mechanism might explain why Tg30 mice do not develop a clinical motor deficit before 8 months of age, ie, starting when the ongoing muscle degeneration leads to the observed hindlimb muscle weakness at this age. This compensation mechanism might also explain the absence of difference in the amplitude of the muscle compound action potential at an early age in $\operatorname{Tg} 30$ mice, because collateral re-innervation may mask the real progress of neuromuscular junction loss. Muscle spontaneous activities were, however, recorded in the majority of mice, already at early ages, indicative of the presence of denervated muscle fibers, as supported also by histological findings in the NMJ. Three-Hertz repetitive stimulations may detect postsynaptic impairment at the neuromuscular junction level, whereas $30-\mathrm{Hz}$ repetitive stimulations, not attempted here, might have disclosed a presynaptic problem similar to the one reported in this study.

\section{Disturbance of Axonal Transports as a Mechanism Leading to NMJ Denervation in Tg30 Mice}

We previously observed in $\operatorname{Tg} 30$ mice the occurrence of axonal spheroids and axonal accumulation of cytoplasmic organelles and neurofilaments in the spinal cord. Accumulations of degraded organelles were also observed in axons in the sciatic nerve. ${ }^{10}$ These ultrastructural abnormalities were indicative of impairment in axonal transports. We further document these disturbances of axoplasmic transport by showing that clusters of cathepsin $\mathrm{B}-$ positive vesicles accumulated in sciatic nerve axons in Tg30 mice. Cathepsin B is a marker of lysosomes/autophagosomes, and disturbances in axoplasmic transport lead to accumulation of cathepsinpositive autophagic vacuoles in experimental models. ${ }^{19}$ Accumulations of autophagic vacuoles in distended, dystrophic neurites is frequently encountered in Alzheimer disease and other neurodegenerative diseases. ${ }^{19,23-26}$ Interestingly, Gallyas-positive aggregates accumulated also in sciatic nerve axons in $\mathrm{Tg} 30$ mice, and might also play a role in impairments in axonal transports. We suggest that the progressive reduction of synaptic vesicles observed in the motor nerve terminals in $\mathrm{Tg} 30$ mice also results from impairments in their axonal transports, and participates in an alteration of synaptic transmission and the functional denervation of NMJ. In the Thy 22 mutant tau transgenic model expressing the same mutant tau 
protein as the present $\mathrm{Tg} 30$ tau model, defects in retrograde transport in the septohippocampal pathway were also previously demonstrated. ${ }^{27}$ In drosophila overexpressing a human tau protein, a disruption of synaptic transmission at the neuromuscular junction was observed as a consequence of disturbance of axonal transports and reduction of the number of mitochondria in axons. ${ }^{28}$

Disturbances of anterograde and retrograde transports have been implicated as a pathogenic mechanism in several neurodegenerative diseases. ${ }^{29-33}$ In models of amyotrophic lateral sclerosis, expression of mutant SOD1 leads to impaired fast axonal transport at an early asymptomatic stage preceding loss of spinal motor neurons. ${ }^{22}$ Mutations in dynein (a motor protein complex that moves along microtubules in the minus-end direction) result in progressive motor neuron degeneration ${ }^{34}$ and the formation of Lewy-like inclusion bodies leading to defects in retrograde transport. ${ }^{35}$ In Alzheimer disease, a reduction of axonal transport is an early pathogenic mechanism, ${ }^{36-38}$ affecting particularly retrograde transport. ${ }^{33}$ Tau proteins play a role in modulation of axonal transport, and tau pathology plays a crucial role in disturbances of these axonal transports in Alzheimer disease. ${ }^{39-43}$ The role of pathological tau at the dendritic level has been pointed out in several studies on tauopathy models. ${ }^{4,45}$ Much evidence points, however, to dying-back axonal degeneration due to axoplasmic transport defects induced by pathological tau as a physiopathological mechanism in Alzheimer disease. ${ }^{46}$ Consistently, the alterations at the level of the NMJ in Tg30tau mice illustrate a toxic effect of abnormal tau at the presynaptic level. A recent study also pointed to disturbances at the presynaptic level in mossy fibers in the hippocampus in a tauopathy model. ${ }^{47}$

To conclude, we show in this study that expression of a human mutant tau protein in the motoneurons and their processes leads to dying-back axonopathy and an early alteration of synaptophysin distribution in motor nerve terminals from 1 month in $\operatorname{Tg} 30$ mice. An axonopathy develops during the following months, characterized by accumulation of aggregates and organelles. These alterations progressively result in a defect in synaptic transmission leading to denervation of NMJ, muscular atrophy, and motor deficit.

We suggest that abnormalities developing at the NMJ in Tg30 mice will be a useful model to unravel mechanisms of synaptic dysfunction resulting from disturbances of axoplasmic transports in neurodegenerative diseases.

\section{Acknowledgment}

We thank Dr. Luc Buée (Université de Lille 2, Lille, France) for providing the $\operatorname{Tg} 30$ mice.

\section{References}

1. Lee VM, Goedert M, Trojanowski JQ: Neurodegenerative tauopathies. Annu Rev Neurosci 2001, 24:1121-1159
2. Neary D, Snowden JS, Mann DM, Northen B, Goulding PJ, Macdermott N: Frontal lobe dementia and motor neuron disease. J Neurol Neurosurg Psychiatry 1990, 53:23-32

3. Hirano A, Malamud N, Elizan TS, Kurland LT: Amyotrophic lateral sclerosis and Parkinsonism-dementia complex on Guam. Further pathologic studies. Arch Neurol 1966, 15:35-51

4. Goedert M, Spillantini MG: Pathogenesis of the tauopathies. J Mol Neurosci 2011, 45:425-431

5. McKhann GM, Albert MS, Grossman M, Miller B, Dickson D, Trojanowski JQ; Work Group on Frontotemporal Dementia and Pick's Disease: Clinical and pathological diagnosis of frontotemporal dementia: report of the Work Group on Frontotemporal Dementia and Pick's Disease. Arch Neurol 2001, 58:1803-1809

6. Buee L, Bussiere T, Buee-Scherrer V, Delacourte A, Hof PR: Tau protein isoforms, phosphorylation and role in neurodegenerative disorders. Brain Res Brain Res Rev 2000, 33:95-130

7. Wang JZ, Liu F: Microtubule-associated protein tau in development, degeneration and protection of neurons. Prog Neurobiol 2008, 85: $148-175$

8. Gotz J, Streffer JR, David D, Schild A, Hoerndli F, Pennanen L, Kurosinski P, Chen F: Transgenic animal models of Alzheimer's disease and related disorders: histopathology, behavior and therapy. Mol Psychiatry 2004, 9:664-683

9. Allen B, Ingram E, Takao M, Smith MJ, Jakes R, Virdee K, Yoshida H, Holzer M, Craxton M, Emson PC, Atzori C, Migheli A, Crowther RA, Ghetti B, Spillantini MG, Goedert M: Abundant tau filaments and nonapoptotic neurodegeneration in transgenic mice expressing human P301S tau protein. J Neurosci 2002, 22:9340-9351

10. Leroy K, Bretteville A, Schindowski K, Gilissen E, Authelet M, De Decker R, Yilmaz Z, Buee L, Brion JP: Early axonopathy preceding neurofibrillary tangles in mutant tau transgenic mice. Am J Pathol 2007, 171:976-992

11. Schindowski K, Bretteville A, Leroy $\mathrm{K}$, Begard S, Brion JP, Hamdane M, Buee L: Alzheimer's disease-like tau neuropathology leads to memory deficits and loss of functional synapses in a novel mutated tau transgenic mouse without any motor deficits. Am J Pathol 2006, 169:599-616

12. Ando K, Leroy K, Heraud C, Yilmaz Z, Authelet M, Suain V, De Decker R, Brion JP: Accelerated human mutant tau aggregation by knocking out murine tau in a transgenic mouse model. Am J Pathol 2011, 178:803-816

13. Besalduch N, Tomas M, Santafe MM, Garcia N, Tomas J, Lanuza MA: Synaptic activity-related classical protein kinase C isoform localization in the adult rat neuromuscular synapse. J Comp Neurol 2010, 518:211-228

14. Lanuza MA, Li MX, Jia M, Kim S, Davenport R, Dunlap V, Nelson PG: Protein kinase C-mediated changes in synaptic efficacy at the neuromuscular junction in vitro: the role of postsynaptic acetylcholine receptors. J Neurosci Res 2000, 61:616-625

15. Audouard E, Schakman O, Rene F, Huettl RE, Huber AB, Loeffler JP, Gailly P, Clotman F: The Onecut transcription factor HNF-6 regulates in motor neurons the formation of the neuromuscular junctions. PLoS One 2012, 7:e50509

16. Paez-Colasante X, Seaberg B, Martinez TL, Kong L, Sumner CJ, Rimer M: Improvement of neuromuscular synaptic phenotypes without enhanced survival and motor function in severe spinal muscular atrophy mice selectively rescued in motor neurons. PLoS One 2013, 8: e75866

17. Leroy K, Ando K, Laporte V, Dedecker R, Suain V, Authelet M, Heraud C, Pierrot N, Yilmaz Z, Octave JN, Brion JP: Lack of tau proteins rescues neuronal cell death and decreases amyloidogenic processing of APP in APP/PS1 mice. Am J Pathol 2012, 181: 1928-1940

18. Kuninaka N, Kawaguchi M, Ogawa M, Sato A, Arima K, Murayama S, Saito Y: Simplification of the modified Gallyas method. Neuropathology 2015, 35:10-15

19. Boland B, Kumar A, Lee S, Platt FM, Wegiel J, Yu WH, Nixon RA: Autophagy induction and autophagosome clearance in neurons: 
relationship to autophagic pathology in Alzheimer's disease. J Neurosci 2008, 28:6926-6937

20. Iguchi Y, Katsuno M, Niwa J, Takagi S, Ishigaki S, Ikenaka K, Kawai K, Watanabe H, Yamanaka K, Takahashi R, Misawa H, Sasaki S, Tanaka F, Sobue G: Loss of TDP-43 causes age-dependent progressive motor neuron degeneration. Brain 2013, 136:1371-1382

21. Vidal M, Morris R, Grosveld F, Spanopoulou E: Tissue-specific control elements of the Thy-1 gene. EMBO J 1990, 9:833-840

22. Warita H, Itoyama $\mathrm{Y}$, Abe K: Selective impairment of fast anterograde axonal transport in the peripheral nerves of asymptomatic transgenic mice with a G93A mutant SOD1 gene. Brain Res 1999, 819:120-131

23. Rubinsztein DC: The roles of intracellular protein-degradation pathways in neurodegeneration. Nature 2006, 443:780-786

24. Yue Z, Wang QJ, Komatsu M: Neuronal autophagy: going the distance to the axon. Autophagy 2008, 4:94-96

25. Katsumata K, Nishiyama J, Inoue $T$, Mizushima N, Takeda J, Yuzaki M: Dynein- and activity-dependent retrograde transport of autophagosomes in neuronal axons. Autophagy 2010, 6:378-385

26. Nixon RA: The role of autophagy in neurodegenerative disease. Nat Med 2013, 19:983-997

27. Belarbi K, Schindowski K, Burnouf S, Caillierez R, Grosjean ME, Demeyer D, Hamdane M, Sergeant N, Blum D, Buee L: Early tau pathology involving the septo-hippocampal pathway in a tau transgenic model: relevance to Alzheimer's disease. Curr Alzheimer Res 2009, 6:152-157

28. Chee F, Mudher A, Newman TA, Cuttle M, Lovestone S, Shepherd D: Overexpression of tau results in defective synaptic transmission in Drosophila neuromuscular junctions. Biochem Soc Trans 2006, 34: 88-90

29. Coleman M: Axon degeneration mechanisms: commonality amid diversity. Nat Rev Neurosci 2005, 6:889-898

30. Roy S, Zhang B, Lee VM, Trojanowski JQ: Axonal transport defects: a common theme in neurodegenerative diseases. Acta Neuropathol 2005, 109:5-13

31. De Vos KJ, Grierson AJ, Ackerley S, Miller CC: Role of axonal transport in neurodegenerative diseases. Annu Rev Neurosci 2008, 31 : $151-173$

32. Morfini GA, Burns M, Binder LI, Kanaan NM, LaPointe N, Bosco DA, Brown RH Jr, Brown H, Tiwari A, Hayward L, Edgar J, Nave KA, Garberrn J, Atagi Y, Song Y, Pigino G, Brady ST: Axonal transport defects in neurodegenerative diseases. J Neurosci 2009, 29:12776-12786

33. Liu XA, Rizzo V, Puthanveettil SV: Pathologies of axonal transport in neurodegenerative diseases. Transl Neurosci 2012, 3:355-372

34. Banks GT, Fisher EM: Cytoplasmic dynein could be key to understanding neurodegeneration. Genome Biol 2008, 9:214

35. Hafezparast M, Klocke R, Ruhrberg C, Marquardt A, AhmadAnnuar A, Bowen S, et al: Mutations in dynein link motor neuron degeneration to defects in retrograde transport. Science 2003, 300: 808-812
36. Stokin GB, Lillo C, Falzone TL, Brusch RG, Rockenstein E, Mount SL, Raman R, Davies P, Masliah E, Williams DS, Goldstein LSB: Axonopathy and transport deficits early in the pathogenesis of Alzheimer's disease. Science 2005, 307:1282-1288

37. Gotz J, Ittner LM, Kins S: Do axonal defects in tau and amyloid precursor protein transgenic animals model axonopathy in Alzheimer's disease? J Neurochem 2006, 98:993-1006

38. Vicario-Orri E, Opazo CM, Munoz FJ: The pathophysiology of axonal transport in Alzheimer's disease. J Alzheimers Dis 2015, 43: $1097-1113$

39. Stamer K, Vogel R, Thies E, Mandelkow E, Mandelkow EM: Tau blocks traffic of organelles, neurofilaments, and APP vesicles in neurons and enhances oxidative stress. J Cell Biol 2002, 156:1051-1063

40. Vossel KA, Zhang K, Brodbeck J, Daub AC, Sharma P, Finkbeiner S, Cui B, Mucke L: Tau reduction prevents Abeta-induced defects in axonal transport. Science 2010, 330:198

41. Kanaan NM, Morfini GA, LaPointe NE, Pigino GF, Patterson KR, Song Y, Andreadis A, Fu Y, Brady ST, Binder LI: Pathogenic forms of tau inhibit kinesin-dependent axonal transport through a mechanism involving activation of axonal phosphotransferases. J Neurosci 2011, 31:9858-9868

42. Morel M, Heraud C, Nicaise C, Suain V, Brion JP: Levels of kinesin light chain and dynein intermediate chain are reduced in the frontal cortex in Alzheimer's disease: implications for axoplasmic transport. Acta Neuropathol 2012, 123:71-84

43. Yu D, LaPointe NE, Guzman E, Pessino V, Wilson L, Feinstein SC, Valentine MT: Tau proteins harboring neurodegeneration-linked mutations impair kinesin translocation in vitro. J Alzheimers Dis 2014, 39:301-314

44. Ittner LM, Ke YD, Delerue F, Bi M, Gladbach A, van Eersel J, Wolfing H, Chieng BC, Christie MJ, Napier IA, Eckert A, Staufenbiel M, Hardeman E, Gotz J: Dendritic function of tau mediates amyloid-beta toxicity in Alzheimer's disease mouse models. Cell 2010, $142: 387-397$

45. Burnouf S, Martire A, Derisbourg M, Laurent C, Belarbi K, Leboucher A, Fernandez-Gomez FJ, Troquier L, Eddarkaoui S, Grosjean ME, Demeyer D, Muhr-Tailleux A, Buisson A, Sergeant N, Hamdane M, Humez S, Popoli P, Buée L, Blum D: NMDA receptor dysfunction contributes to impaired brain-derived neurotrophic factorinduced facilitation of hippocampal synaptic transmission in a Tau transgenic model. Aging Cell 2013, 12:11-23

46. Kanaan NM, Pigino GF, Brady ST, Lazarov O, Binder LI, Morfini GA: Axonal degeneration in Alzheimer's disease: when signaling abnormalities meet the axonal transport system. Exp Neurol 2013, 246: $44-53$

47. Decker JM, Kruger L, Sydow A, Zhao S, Frotscher M, Mandelkow E, Mandelkow EM: Pro-aggregant Tau impairs mossy fiber plasticity due to structural changes and $\mathrm{Ca}++$ dysregulation. Acta Neuropathol Commun 2015, 3:23 